Rowan University

Rowan Digital Works

Henry M. Rowan College of Engineering Faculty Scholarship

$12-28-2020$

\title{
The mathematical relationship among normal patellar dimensions, to find the pre-diseased patellar thickness in different populations
}

\author{
Mahdie Kerdari \\ Shima Rastegar \\ Yasmeen Mustafa \\ Mohammadreza Abbassian \\ Armin Aalami Harandi
}

See next page for additional authors

Follow this and additional works at: https://rdw.rowan.edu/engineering_facpub

Digitalrt of the Biomedical Engineering and Bioengineering Commons

Commons

\section{Network \\ Recommended Citation}

Regdari, Mahdie; Rastegar, Shima; Mustafa, Yasmeen; Abbassian, Mohammadreza; Aalami Harandi, Armin; Stahle, Mary M.; Hube, Robert; and Hosseinzadeh, Hamid RS, "The mathematical relationship among normal patellar dimensions, to find the pre-diseased patellar thickness in different populations" (2020). Henry M. Rowan College of Engineering Faculty Scholarship. 130.

https://rdw.rowan.edu/engineering_facpub/130

This Article is brought to you for free and open access by the Henry M. Rowan College of Engineering at Rowan Digital Works. It has been accepted for inclusion in Henry M. Rowan College of Engineering Faculty Scholarship by an authorized administrator of Rowan Digital Works. 


\section{Authors}

Mahdie Kerdari, Shima Rastegar, Yasmeen Mustafa, Mohammadreza Abbassian, Armin Aalami Harandi, Mary M. Stahle, Robert Hube, and Hamid RS Hosseinzadeh 


\title{
The mathematical relationship among normal patellar dimensions, to find the pre-diseased patellar thickness in different populations
}

\author{
Mahdie Kerdari $\mathrm{MD}^{1}$, Shima Rastegar $\mathrm{MD}^{2}$, Yasmeen Mustafa $\mathrm{MD}^{1}$, Mohammadreza Abbassian $\mathrm{MD}^{3}$, Armin \\ Aalami Harandi $\mathrm{MD}^{4}$, Mary M. Staehle $\mathrm{PhD}^{5}$, Robert Hube $\mathrm{MD}^{6}$, Hamid RS Hosseinzadeh MD* \\ ${ }^{1}$ Post-Doctoral Research Fellow, Orthopedic Research Group, Rowan University, Camden, NJ, USA \\ ${ }^{2}$ Resident physician, Department of pathology and laboratory medicine, Rutgers University, NJ, USA \\ ${ }^{3}$ Associate professor, Orthopedic surgeon, Shahid Beheshti Medical University, Tehran, Iran \\ Post-Doctoral Research Fellow, Center for advanced orthopedic studies, Harvard medical school, Boston, MA, USA \\ ${ }^{4}$ Instructor, Orthopedic surgeon, Department of Orthopedic Surgery, University of Virginia, Virginia, USA \\ ${ }^{5}$ Associate professor, Department of Biomedical Engineering, Rowan University, Glassboro, NJ, USA \\ ${ }^{6}$ Professor of Orthopedic Surgery, Charité -University Medicine Berlin, Director of Center of Joint Replacement, \\ OCM/SANA Campus Munich, Germany \\ ${ }^{7}$ Associate professor, Orthopedic surgeon, orthopedic research group, rowan university, Camden, NJ, USA \\ * Corresponding author, email: hh@scifox.org
}

\section{ABSTRACT}

Whether resurfacing or not resurfacing the patella during total knee arthroplasty (TKA) still is a challenge to orthopedic surgeons. A significant reason for this controversy is the far from perfect outcomes of both techniques, resulting from inadequate knowledge of normal patellar dimensions in a diseased one. The primary purpose of the current study is to find the pre-diseased patellar dimensions and the ethnic differences in patellar dimensions.

We measured the patella's dimensions on 927 normal young adult knee MRIs from seven different ethnicities. Besides comparing the dimensions between sexes, ages, and sides, we analyzed the differences among ethnic groups.

The average thickness was $25.12 \pm 2.33 \mathrm{~mm}$; the average width was $44.57 \pm 4.32 \mathrm{~mm}$, the average articular surface length was $32.69 \pm 3.75 \mathrm{~mm}$, with significant gender, age, and ethnic differences. There were also significant differences in dimensions among ethnic groups, except for between the Indians and Far Eastern Asians and between the Arabs and North Africans.

We could also find a robust mathematical relationship between the patella's width, length, and thickness.

The ethnic differences in patellar dimensions found in this study can help optimize surgical technique and implant designs for patellar resurfacing.

The mathematical equation will help the surgeons find the normal, pre-diseased patella thickness to prevent over-or understuffing during the patellar resurfacing.

Keywords: Patella, dimension, ethnic anatomy, patellar thickness, ridge-offset ratio

\section{Introduction}

During total knee arthroplasty (TKA), the final decision to perform the patellar resurfacing is still controversial among the orthopedic surgeons, as evidenced by unsatisfactory clinical and functional outcomes of either procedure ${ }^{1,2}$. According to evidence, up to $7 \%$ of TKAs have required revision surgery due to unsatisfactory results after five years of primary TKA ${ }^{3}$. Among all factors, the patellofemoral joint issues accounted as the principal cause for up to $8 \%$ of the cases requiring revision surgery ${ }^{4,5}$.

Persistent anterior knee pain is a major reason for the revision surgery if surgeons select not to perform the patellar resurfacing. The patients who underwent failed resurfaced patella TKAs suffer from persistent pain and had to perform revision surgery mainly due to fracture, dislocation of the patella, and implant failure 6,7 . There are anatomical and mechanical factors in both resurfaced and non-resurfaced patellae (i.e., patellar instability, changes in joint reaction force, and the muscular lever arm), that cause the failure of TKAs ${ }^{8,9}$.

There was no financial support for this research.

The authors report no conflicts of interest regarding this manuscript. None of the authors, nor their institutions, received any payment or services from a third party for any aspect of the submitted work. 
Mechanical issues due to ridge offset errors and alterations in patella thickness (under-stuffing or over-stuffing) not only should be assessed in the resurfaced patella TKAs but also must be considered in non-resurfaced patellar TKAs ${ }^{10-12}$.

Interestingly, regardless of different reasons for the failed TKAs in both resurfaced and non-resurfaced patella, due to the controversy in current evidence, neither of these two approaches has been demonstrated as superior ${ }^{13-15}$.

Since limited information is available about the relationship between the different patellar dimensions, surgeons use their personal preferences instead of following scientific guidelines ${ }^{16}$. Besides, they do not optimize the anatomical/biomechanical patellar properties as a standard operating procedure. This lack of optimization makes the TKA surgeries more challenging for further optimizing the patellofemoral joint kinematics, which increases the risk of revision surgery ${ }^{17}$. Undoubtedly, advanced knowledge about the patella's anatomy and biomechanics in concert with proper surgical technique and prostheses design must be considered when deciding to resurface the patella ${ }^{18,19}$.

No conclusive evidence exists to predict the normal patellar thickness during resurfacing. This is driven by performing a limited sample size, inaccurate measurement methods, and unsatisfactory statistical analysis, making these studies neither accurate nor reliable for generalizing to the entire population ${ }^{20,21}$. Additionally, the previous studies had paid little attention to gender, age, and ethnicity differences ${ }^{22}$.

This study's objectives are: 1) determining the normal patellar dimensions (i.e., length, width, and thickness) as a function of age, gender, and ethnicity and, 2) utilize this data to design a mathematical relationship for predicting the normal patellar shape and thickness. The results of this study suggest a new modus operandi for future patellar resurfacing techniques, thereby avoids miscalculation of the patellar thickness and leads to best practice in implant fitting.

\section{Methods}

In this retrospective/cross-sectional study, we selected 927 adult knee Magnetic Resonance Images (MRI) out of 22450 knee MRIs. The exclusion criteria were age less than 14 and higher than 63 years, presence of fracture, tumor, osteoarticular abnormalities or severe osteoarthritis, and operated patella, and inappropriate MRI acquisition technique, especially those MRIs in which the sagittal, coronal and axial planes were more than 10 degrees off the body planes. All selected MRIs had a $5 \mathrm{~mm}$ cut increment.

All images were unidentified except for each individual's demographic information (sex, age, side, and ethnicity). We used an image processing software (Jessy software) for measuring the patellar dimensions in this study.

We measured three dimensions and one ratio in each patella: thickness (anteroposterior diameter), width (mediolateral diameter of the articular surface), length (superoinferior diameter of the articular surface), and patellar ridge offset. Since the position of the patella relative to femoral condyles is not fixed and can change due to muscle contractions or disease processes, we could not select a fixed MRI cut for each dimension; hence we selected the best MRI cut based on the patella, after checking all cuts in that plane, chose the cut showing the intended dimension in its broadest. We used the axial cuts for thickness and width, and for length, we used the sagittal cuts. The ridge offset ratio (patellar ridge position relative to the width from the lateral side) was measured in axial cuts.

Using the selected axial images, the patellar thickness was measured by drawing a line from the most prominent part of patellar cartilage to the anterior patellar cortex, perpendicular to the medial/lateral axis of the patella (Fig 1-A). The patellar width was measured on the selected axial images by drawing a line that was drawn between the most medial and the most lateral bony structures of the patella at the articular cartilage surface (Fig 1-A). The patellar length was measured on selected sagittal images, drawing a straight vertical line from the most proximal edge of the patellar articular surface cartilage to the most distal aspect of the patellar cartilage (Fig 1-B). We measured the patellar ridge offset ratio on the axial images selected for patellar width by drawing a line from the articular cartilage's most prominent point perpendicular to the line showing the articular width. The distance from the intersection of these two lines from the lateral end of the articular surface was divided by the patellar articular width (Fig 1-C). 
We also statistically analyzed the data to find any reliable correlation between different patellar dimensions to portray the patellar shape according to the specific gender, age, and ethnic groups.

All statistical analysis was performed using the SPSS 24.0 software program with the level of significance $\alpha=0.05$.

The normal distribution of all variables was evaluated using a Shapiro Wilks test with a significance level of $\alpha=0.05$. Using an independent t-test, we analyzed gender differences for all parameters to determine if statistically significant sexual dimorphism existed. The mean values of all parameters were compared among different sexes, sides, age groups, and ethnic groups using a one-way ANOVA. We used Pearson correlation to find out the thickness to width, thickness to the articular length, and articular length to width relationship.
Inter-observer and intra-observer correlation: The study's reproducibility was checked for each parameter by re-measuring about $13 \%$ of MRIs randomly selected from the main population. Both first and second observers were physicians who were trained for the specific measurements.

\section{Results}

Among 927 measured MRIs, there were 580 (62.57\%) males and 347 (37.43\%) females.

We also divided the samples into seven ethnic groups: India, Far eastern Asia, North Africa, Iran, West Asia, Arab, and Europe. We had 94 (10.14\%) cases in the Indian group, 98 (10.57\%) in Far eastern Asians, 127 (13.70\%) in North Africans, 220 (23.73\%) in Iranians, 49 (5.29\%) in west Asians, 213 (22.98\%) in Arabs, and 126 13.59\%) in Europeans. The demographic data is provided in table 1.
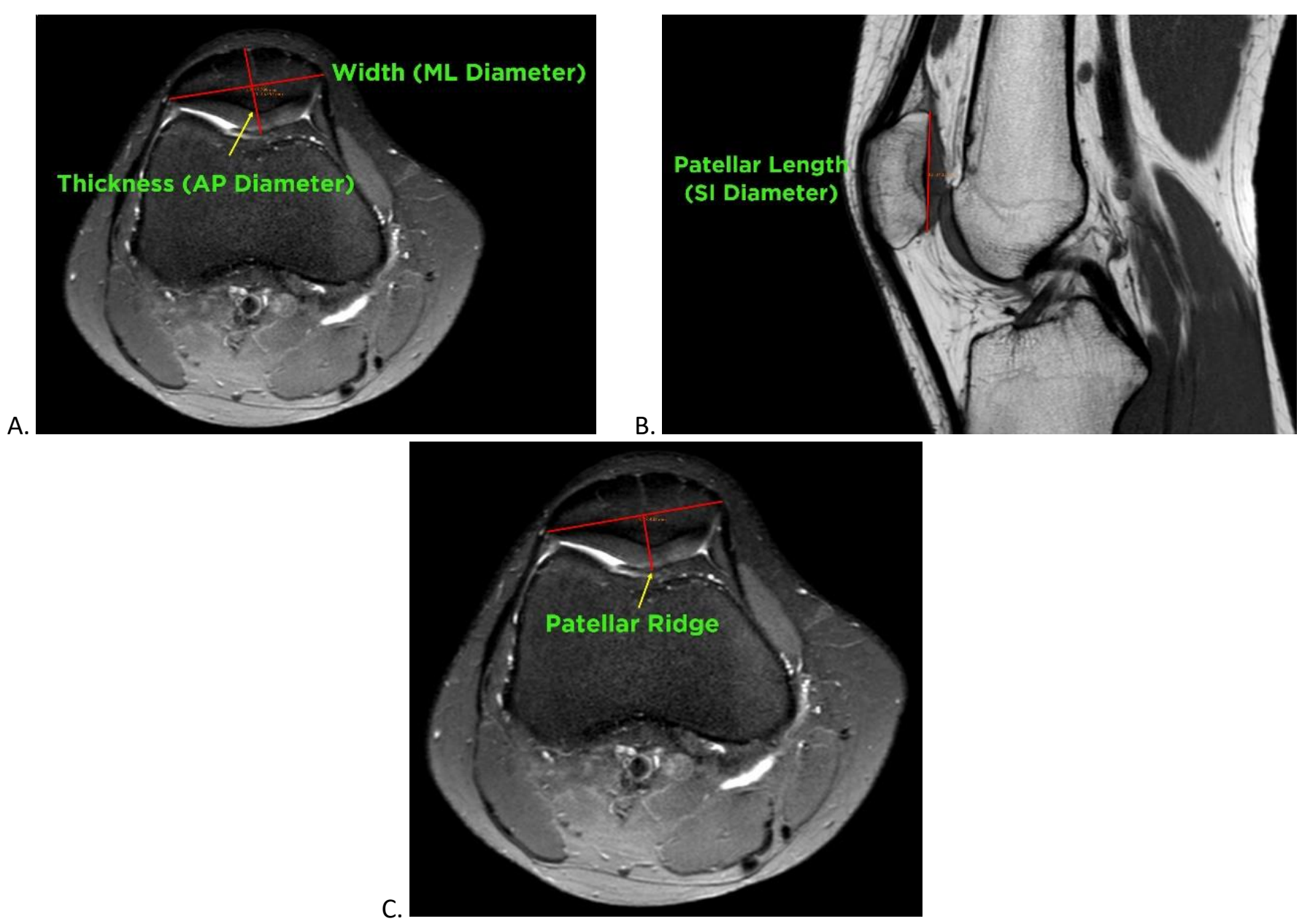

Figure 1: The method of measurement of different patellar dimensions on selected MRIs: A) Thickness and width B) Length and C) ridge offset ratio. 
Table 1: The demographic data of all the cases included in the study.

\begin{tabular}{|c|c|c|c|c|c|c|c|c|c|c|c|}
\hline & & \multirow{2}{*}{$\begin{array}{c}\text { Total } \\
\text { Number }\end{array}$} & \multicolumn{5}{|c|}{ Age (yr) } & \multicolumn{2}{|c|}{ Side } & \multicolumn{2}{|c|}{ Sex } \\
\hline & & & $14-23$ & $24-33$ & $34-43$ & $44-53$ & $54-63$ & Left & Right & Female & Male \\
\hline \multicolumn{2}{|l|}{ All Cases } & 927 & $\begin{array}{c}117 \\
(12.62 \%)\end{array}$ & $\begin{array}{c}278 \\
(29.99 \%)\end{array}$ & $\begin{array}{c}248 \\
(26.75 \%)\end{array}$ & $\begin{array}{c}161 \\
(17.37 \%)\end{array}$ & $\begin{array}{c}123 \\
(13.27 \%)\end{array}$ & $\begin{array}{c}449 \\
(53.83 \%)\end{array}$ & $\begin{array}{c}428 \\
(46.17 \%)\end{array}$ & $\begin{array}{c}347 \\
(37.43 \%)\end{array}$ & $\begin{array}{c}580 \\
(62.57 \%)\end{array}$ \\
\hline \multirow[t]{7}{*}{$\begin{array}{l}\text { Ethnic } \\
\text { Groups }\end{array}$} & Indians & $\begin{array}{c}94 \\
(10.14 \%)\end{array}$ & $\begin{array}{c}12 \\
(12.77 \%)\end{array}$ & $\begin{array}{c}27 \\
(28.72 \%)\end{array}$ & $\begin{array}{c}30 \\
(31.91 \%)\end{array}$ & $\begin{array}{c}15 \\
(15.96 \%)\end{array}$ & $\begin{array}{c}10 \\
(10.64 \%)\end{array}$ & $\begin{array}{c}50 \\
(53.19 \%)\end{array}$ & $\begin{array}{c}44 \\
(46.81 \%)\end{array}$ & $\begin{array}{c}43 \\
(45.74 \%)\end{array}$ & $\begin{array}{c}51 \\
(54.26 \%)\end{array}$ \\
\hline & $\begin{array}{l}\text { Far } \\
\text { Eastern } \\
\text { Asians }\end{array}$ & $\begin{array}{c}98 \\
(10.57 \%)\end{array}$ & $\begin{array}{c}8 \\
(8.16 \%)\end{array}$ & $\begin{array}{c}24 \\
(24.49 \%)\end{array}$ & $\begin{array}{c}7 \\
(7.14 \%)\end{array}$ & $\begin{array}{c}10 \\
(10.20 \%)\end{array}$ & 49 (50\%) & $\begin{array}{c}52 \\
(53.06 \%)\end{array}$ & $\begin{array}{c}46 \\
(46.94 \%)\end{array}$ & $\begin{array}{c}43 \\
(43.88 \%)\end{array}$ & $\begin{array}{c}55 \\
(56.12 \%)\end{array}$ \\
\hline & $\begin{array}{l}\text { North } \\
\text { Africans }\end{array}$ & $\begin{array}{c}127 \\
(13.70 \%)\end{array}$ & $\begin{array}{c}8 \\
(6.30 \%)\end{array}$ & $\begin{array}{c}32 \\
(25.20 \%)\end{array}$ & $\begin{array}{c}44 \\
(34.65 \%)\end{array}$ & $\begin{array}{c}31 \\
(24.41 \%)\end{array}$ & $\begin{array}{c}12 \\
(9.45 \%)\end{array}$ & $\begin{array}{c}69 \\
(54.33 \%)\end{array}$ & $\begin{array}{c}58 \\
(45.67 \%)\end{array}$ & $\begin{array}{c}59 \\
(46.46 \%)\end{array}$ & $\begin{array}{c}68 \\
(53.54 \%)\end{array}$ \\
\hline & Iranians & $\begin{array}{c}220 \\
(23.73 \%)\end{array}$ & $\begin{array}{c}14 \\
(6.36 \%)\end{array}$ & $\begin{array}{c}61 \\
(27.73 \%)\end{array}$ & $\begin{array}{c}64 \\
(29.09 \%)\end{array}$ & $\begin{array}{c}54 \\
(24.55 \%)\end{array}$ & $\begin{array}{c}27 \\
(12.27 \%)\end{array}$ & $\begin{array}{c}118 \\
(53.64 \%)\end{array}$ & $\begin{array}{c}102 \\
(46.36 \%)\end{array}$ & $\begin{array}{c}87 \\
(39.55 \%)\end{array}$ & $\begin{array}{c}133 \\
(60.45 \%)\end{array}$ \\
\hline & $\begin{array}{l}\text { West } \\
\text { Asians }\end{array}$ & $\begin{array}{c}49 \\
(5.29 \%)\end{array}$ & $\begin{array}{c}2 \\
(4.08 \%)\end{array}$ & $\begin{array}{c}19 \\
(38.78 \%)\end{array}$ & $\begin{array}{c}15 \\
(30.61 \%)\end{array}$ & $\begin{array}{c}10 \\
(20.41 \%)\end{array}$ & $\begin{array}{c}3 \\
(6.12 \%)\end{array}$ & $\begin{array}{c}25 \\
(51.02 \%)\end{array}$ & $\begin{array}{c}24 \\
(48.98 \%)\end{array}$ & $\begin{array}{c}17 \\
(34.69 \%)\end{array}$ & $\begin{array}{c}32 \\
(65.31 \%)\end{array}$ \\
\hline & Arabs & $\begin{array}{c}213 \\
(22.98 \%)\end{array}$ & $\begin{array}{c}19 \\
(8.92 \%)\end{array}$ & $\begin{array}{c}66 \\
(30.99 \%)\end{array}$ & $\begin{array}{c}74 \\
(34.74 \%)\end{array}$ & $\begin{array}{c}34 \\
(15.96 \%)\end{array}$ & $\begin{array}{c}20 \\
(9.39 \%)\end{array}$ & $\begin{array}{c}118 \\
(55.40 \%)\end{array}$ & $\begin{array}{c}95 \\
(44.60 \%)\end{array}$ & $\begin{array}{c}46 \\
(21.59 \%)\end{array}$ & $\begin{array}{c}167 \\
(78.41 \%)\end{array}$ \\
\hline & Europeans & $\begin{array}{c}126 \\
(13.59 \%)\end{array}$ & $\begin{array}{c}54 \\
(42.86 \%)\end{array}$ & $\begin{array}{c}49 \\
(38.89 \%)\end{array}$ & $\begin{array}{c}14 \\
(11.11 \%)\end{array}$ & $\begin{array}{c}9 \\
(7.14 \%)\end{array}$ & $\begin{array}{c}0 \\
(0.00 \%)\end{array}$ & $\begin{array}{c}67 \\
(53.17 \%)\end{array}$ & $\begin{array}{c}59 \\
(46.83 \%)\end{array}$ & $\begin{array}{c}52 \\
(41.27 \%)\end{array}$ & $\begin{array}{c}74 \\
(58.73 \%)\end{array}$ \\
\hline
\end{tabular}

Among all cases, the average thickness was $25.12 \pm 2.33 \mathrm{~mm}$, the average width was $44.57 \pm 4.32$ $\mathrm{mm}$, and the average articular surface length was $32.69 \pm 3.75 \mathrm{~mm}$. There was significant gender, age, and ethnic differences in patellar dimensions (Table 2).

In general, all patellar dimensions (thickness, length, and width) were significantly larger in males (thickness: $26.06 \pm 2.02 \mathrm{~mm}$; length: $33.82 \pm 3.52 \mathrm{~mm}$; width: $46.48 \pm 3.62 \mathrm{~mm}$ ) than females (thickness: $23.53 \pm 1.94 \mathrm{~mm}$; length: $30.80 \pm 3.33 \mathrm{~mm}$; width: $41.39 \pm 3.42 \mathrm{~mm}$ ) (Table 2) (p-value $<0.00001$ ).

Our findings showed all patellar dimensions are not significantly different in different ages from 14 to 53 years, but all of them significantly decreased in patients older than 54 years (Table 2) ( $p$-value $<0.00001$ ).

There were no significant differences among patellar dimensions in left- and right-side knees (Table 2) ( $p$ value $<0.00001$ ).

The lateral facet occupied $53 \% \pm 0.06$ of the entire patellar width (Ridge offset ratio). This parameter was significantly larger in females $(55 \% \pm 0.05)$ than males $(53 \% \pm 0.05)$ and significantly smaller in middle age people (34-43 yr) than both younger and older people. There was no significant difference in the ridge offset ratio in the left and right knees ( $p$-value $<0.00001)$.
Patellar dimensions in different ethnic groups (Table 3)

The thickest patella was in Iranians $(26.15 \pm 2.39 \mathrm{~mm})$ followed by Europeans $(25.76 \pm 1.91 \mathrm{~mm})$, Arabs $(25.13 \pm 1.88 \mathrm{~mm})$, North Africans $(25.13 \pm 2.71 \mathrm{~mm})$, Indians $(24.03 \pm 2.04 \mathrm{~mm})$, West Asians $(23.81 \pm 1.82$ $\mathrm{mm}$ ), and Far East Asians (23.63 $\pm 2.07 \mathrm{~mm}$ ). (Fig 2-A)

The largest width of the patella was in the Europeans $(45.76 \pm 3.71 \mathrm{~mm})$, followed by Iranians $(45.60 \pm 4.44$ $\mathrm{mm})$, Arabs $(45.25 \pm 3.56 \mathrm{~mm})$, North Africans $(44.42 \pm 4.86 \mathrm{~mm})$, Indians $(42.87 \pm 3.99 \mathrm{~mm})$, Far East Asians $(42.42 \pm 4.37 \mathrm{~mm})$, and West Asians $(41.94 \pm 3.70 \mathrm{~mm})$. (Fig 2-B)

The average length of patellar articular surface was the largest in the Iranians $(34.74 \pm 3.67 \mathrm{~mm})$, followed by Europeans $(33.53 \pm 2.91 \mathrm{~mm})$, North Africans $(33.22 \pm 4.49 \mathrm{~mm})$, Arabs $(32.03 \pm 3.27 \mathrm{~mm})$, West Asians $(31.30 \pm 2.69 \mathrm{~mm})$, Indians $(30.63 \pm 3.31 \mathrm{~mm})$, and Far East Asians (30.45 $\pm 2.71 \mathrm{~mm}$ ). (Fig 2-C)

The average ridge offset ratio in Indians was $0.56 \pm 0.04$, in Far East Asians was 0.55 \pm 0.04 , in North Africans was $0.55 \pm 0.05$, in Iranian was $0.54 \pm 0.04$, in West Asians was $0.53 \pm 0.06$, in Arabs was $0.49 \pm 0.07$ and in Europeans 0.56 \pm 0.05 . (Fig 2-D)

The one-way ANOVA test results on the thickness, width, and length of the patella in ethnic groups show significant differences in these parameters among most selected ethnic groups. The exceptions are no 
significant differences between Indians and Far east Asians and between North Africans and Arabs. Although there are differences among the patellar dimensions between Iranians and Europeans, the differences' significance is not robust.

Our results show no significant differences in the patellar ridge offset ratio among different ethnic groups except for the Arab people. In other ethnicities, the lateral facet covers more than $50 \%$ of the patella's width, while in the Arab people, the ridge offset ratio is less than $50 \%$. So, in this group of people, the ridge is lateral to the patella's vertical midline. In contrast, in other ethnicities, the ridge is medial to the vertical midline of the patella.

\section{The ratios between patellar dimensions}

We tried to find a mathematical relationship among patellar dimensions to calculate any dimension with two others.

Using the Pearson correlation, we found a moderate to good positive correlation coefficient between patellar dimensions: the thickness-width $(r=0.6)$, thickness-length $(r=0.8)$, and length-width $(r=0.44)$ correlated with a significant level of 0.01 .

Since the smallest standard deviation for patellar thickness among different ethnic groups was 1.82 $\mathrm{mm}$, any patellar thickness calculation deviated less than $1.82 \mathrm{~mm}$ was determined as acceptable.

Table 2: The measured dimension of the patella in all cases

\begin{tabular}{llllll}
\hline Parameter & & Thickness $(\mathbf{m m})$ & Width $(\mathbf{m m})$ & Length $(\mathbf{m m})$ & Ridge Offset Ratio \\
\hline Total & & $25.12 \pm 2.33$ & $44.57 \pm 4.32$ & $32.69 \pm 3.75$ & $0.53 \pm 0.06$ \\
\hline Age $(\mathbf{y r})$ & $\mathbf{1 4 - 2 3}$ & $25.30 \pm 2.04$ & $44.90 \pm 3.77$ & $33.03 \pm 3.18$ & $0.55 \pm 0.06$ \\
\cline { 2 - 6 } & $\mathbf{2 4 - 3 3}$ & $25.33 \pm 2.39$ & $44.87 \pm 4.49$ & $32.96 \pm 3.89$ & $0.53 \pm 0.06$ \\
\cline { 2 - 6 } & $\mathbf{3 4 - 4 3}$ & $25.37 \pm 2.28$ & $45.03 \pm 4.25$ & $33.03 \pm 3.74$ & $0.52 \pm 0.07$ \\
\cline { 2 - 6 } & $\mathbf{4 4 - 5 3}$ & $25.30 \pm 2.27$ & $44.98 \pm 4.14$ & $32.75 \pm 3.89$ & $0.53 \pm 0.06$ \\
\hline \multirow{2}{*}{ Side } & $\mathbf{5 4 - 6 3}$ & $23.72 \pm 2.20$ & $42.12 \pm 4.00$ & $30.99 \pm 3.32$ & $0.54 \pm 0.05$ \\
\hline \multirow{2}{*}{ Sex } & Left & $25.10 \pm 2.37$ & $44.56 \pm 4.33$ & $32.67 \pm 3.78$ & $0.53 \pm 0.06$ \\
\cline { 2 - 6 } & Right & $25.14 \pm 2.29$ & $44.59 \pm 4.31$ & $32.72 \pm 3.72$ & $0.54 \pm 0.06$ \\
\hline & Female & $23.54 \pm 0.93$ & $41.39 \pm 3.42$ & $30.80 \pm 3.33$ & $0.55 \pm 0.05$ \\
\hline
\end{tabular}

Table 3: The measured dimensions of the patella in different ethnic groups

\begin{tabular}{lcccc}
\hline Ethnic Groups & $\begin{array}{c}\text { Thickness } \\
(\mathbf{m m})\end{array}$ & Width $(\mathbf{m m})$ & Length $(\mathbf{m m})$ & Ridge Offset Ratio \\
\hline Indians & $24.03 \pm 2.04$ & $42.87 \pm 3.99$ & $30.63 \pm 3.31$ & $0.56 \pm 0.05$ \\
\hline $\begin{array}{l}\text { Far Eastern } \\
\text { Asians }\end{array}$ & $23.63 \pm 2.07$ & $42.42 \pm 4.37$ & $30.45 \pm 2.71$ & $0.55 \pm 0.04$ \\
\hline North Africans & $25.13 \pm 2.71$ & $44.42 \pm 4.86$ & $33.22 \pm 4.49$ & $0.55 \pm 0.05$ \\
\hline Iranians & $26.15 \pm 2.39$ & $45.60 \pm 4.44$ & $34.74 \pm 3.67$ & $0.54 \pm 0.05$ \\
\hline West Asians & $23.81 \pm 1.82$ & $41.94 \pm 3.70$ & $31.30 \pm 2.69$ & $0.53 \pm 0.06$ \\
\hline Arabs & $25.13 \pm 1.88$ & $45.25 \pm 3.56$ & $32.03 \pm 3.27$ & $0.49 \pm 0.07$ \\
\hline Europeans & $25.76 \pm 1.91$ & $45.76 \pm 3.71$ & $33.53 \pm 2.91$ & $0.56 \pm 0.05$ \\
\hline
\end{tabular}


A.
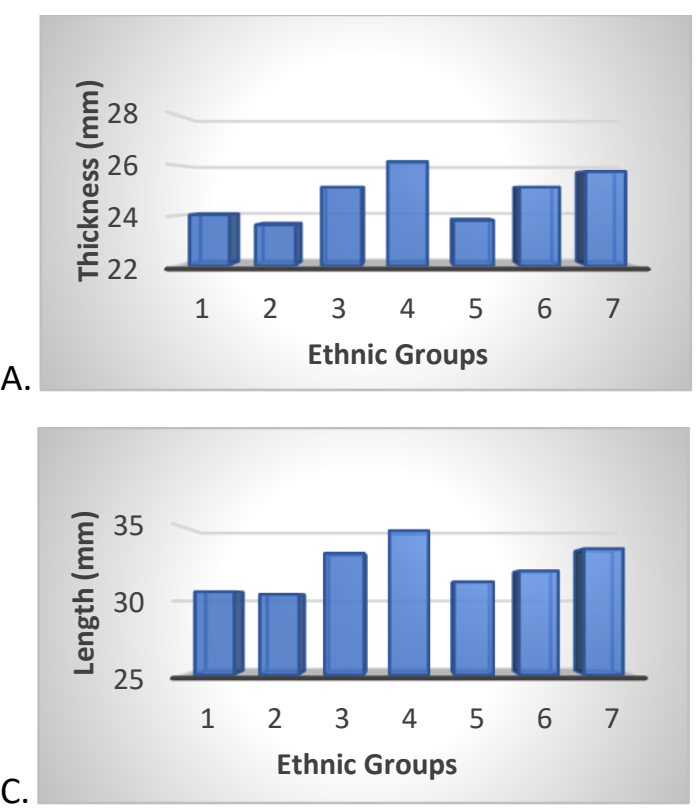
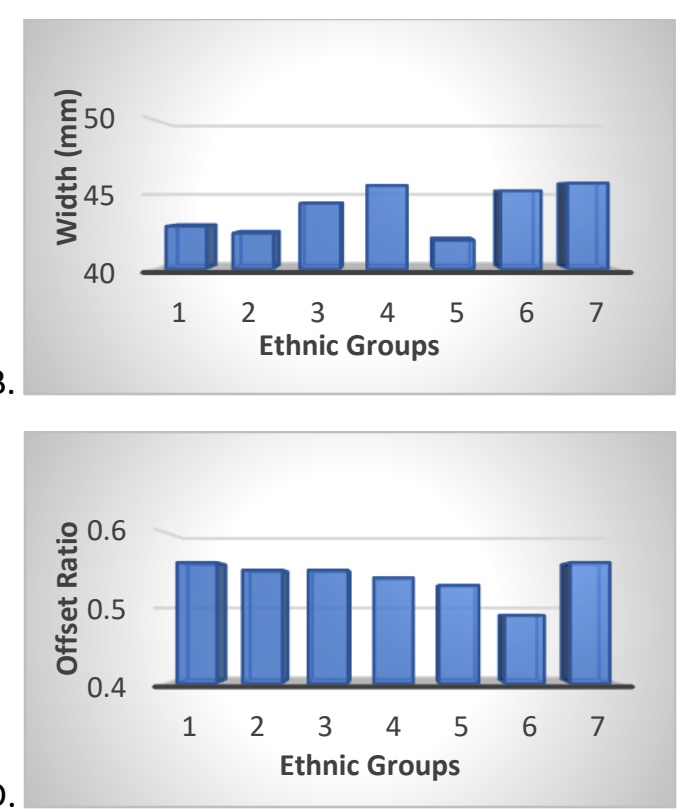

Figure 2: The distribution of Patellar thickness (A), articular width (B), articular length (C), and ridge offset ratio (D) in ethnic groups (Group 1: Indians; Group 2: Far East Asians; Group 3: North Africans; Group 4: Iranians; Group 5: West Asians; Group 6: Arabs; Group 7: Europeans).

Based on the correlation between patellar dimensions, we found the following equation, which calculates the thickness from patellar width and length with great accuracy:

$$
A P=\frac{-S I \pm \sqrt{S I^{2}+4 S I \times M L}}{2} \times k
$$

where AP is the thickness, $\mathrm{SI}$ is the superoinferior length of the patellar articular surface, and $\mathrm{ML}$ is the mediolateral length of the patellar articular surface (all in $\mathrm{mm}$ ). $\mathrm{K}$ is a constant adjusting the equation further for age, sex, and ethnicity.

By this equation, in 927 samples, the thickness was measured within $\pm 1.82 \mathrm{~mm}$ of measured thickness in 919 cases (99.13\%) and within only $1 \mathrm{~mm}$ of the measured thickness in 864 cases (93.20\%). (Fig 3 and 4)

\section{Discussion}

When the surgeon decides to perform a patellar resurfacing, the major problem is finding the normal, pre-disease patellar dimensions, specifically the thickness and ridge position. The reason is when the patient is considered for TKA; in most cases, the patellar cartilage is already eroded; hence, determining the normal, pre-disease patellar thickness and the ridge position is not feasible. In this study, we tried to find a mathematical relationship among patellar dimensions to enable the surgeons to find the pre-disease patellar thickness in a diseased, already eroded patella, using the intact dimensions.

Several studies have evaluated the patella's normal morphology; however, few investigations have investigated the relationship of different patellar dimensions in normal populations.

Sullivan et al. in 2018 found a strong correlation between patellar thickness and width in 75 normal patellae to represent a new guide for accurate restoration of the patellar thickness during TKA. But they carried out their investigation on a small sample group (75 normal patellae). Moreover, they did not take gender, age, and ethnicity into account ${ }^{23}$. In 2008, Iranpour et al. evaluated the patella's thickness-width correlation in 37 normal knees of British people older than 55 years using CT scan images ${ }^{20}$. Despite finding an excellent widththickness correlation, their study used knee CT scans, which is not accurate enough to identify the cartilage. So, it appears that the thickness they considered is not the actual patellar thickness, which includes the cartilage. 


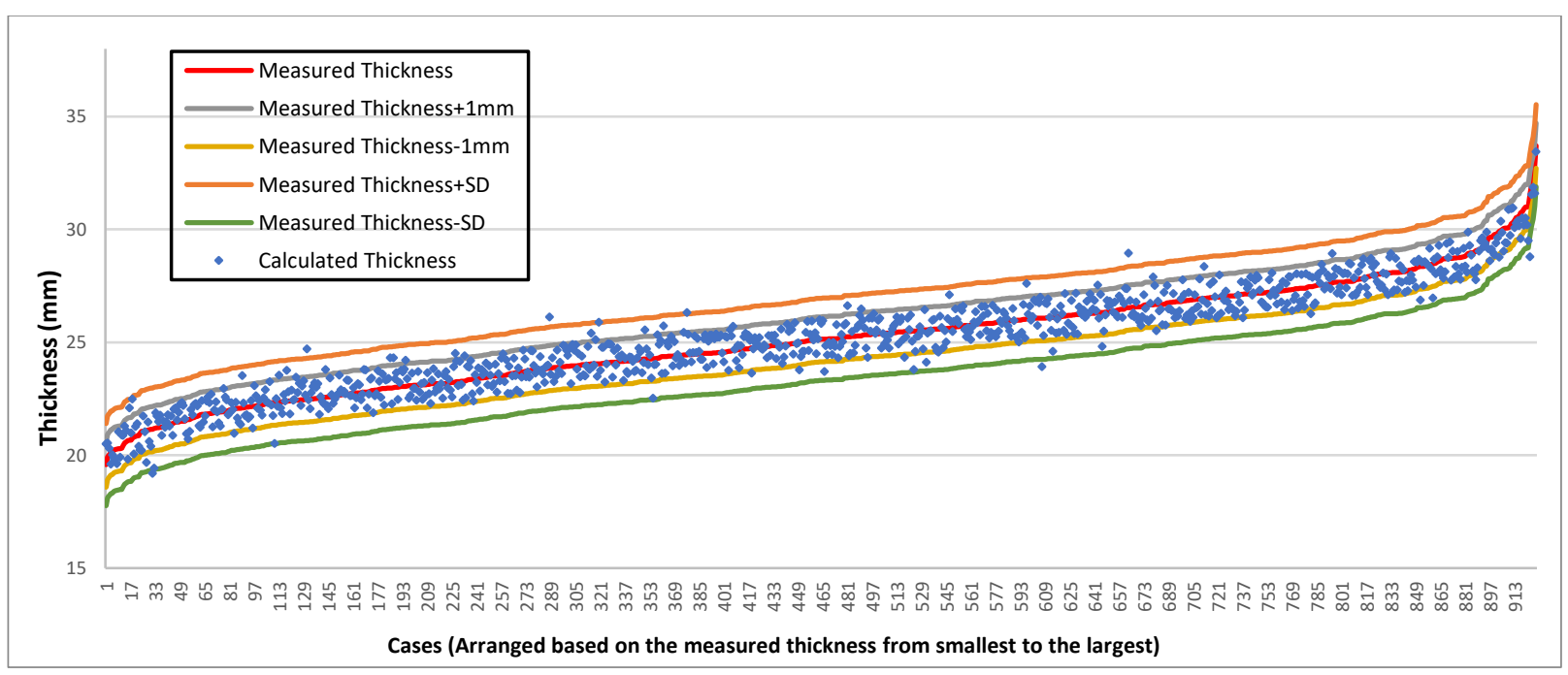

Figure 3: The distribution of the calculated patellar thickness by equation 1 compared to the measured thickness of the same patella

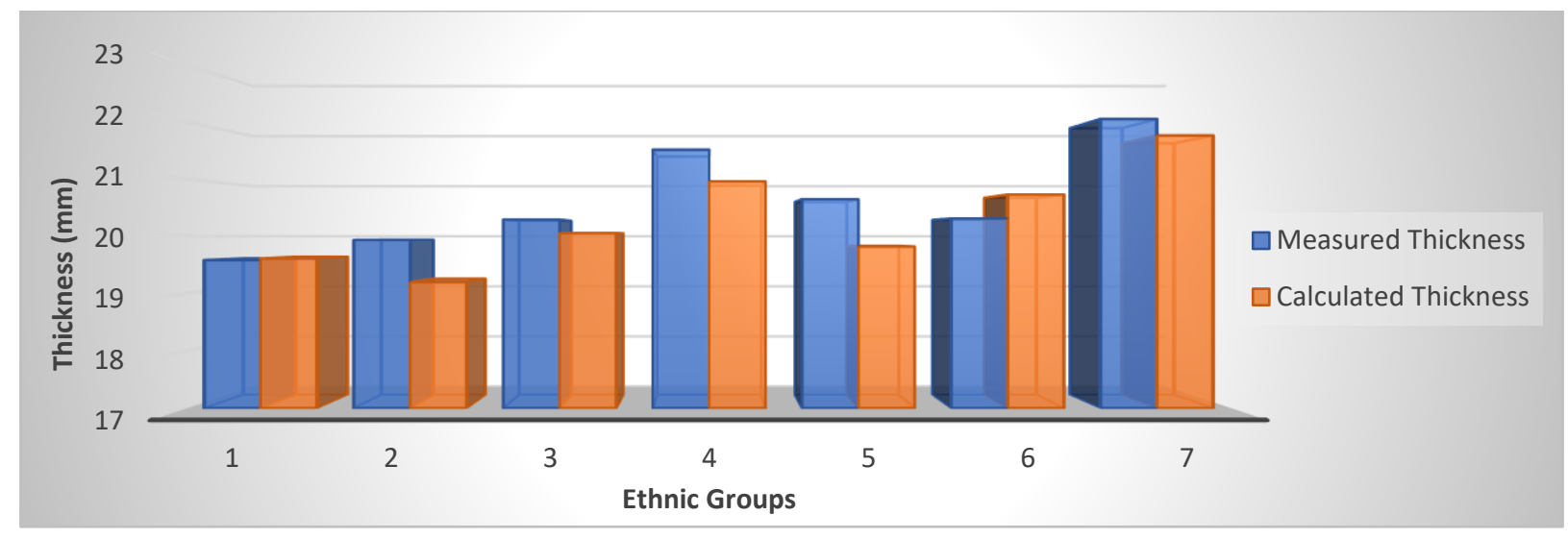

Figure 4: A comparison among measured and calculated patellar thickness in ethnic groups (Group 1: Indians; Group 2: Far East Asians; Group 3: North Africans; Group 4: Iranians; Group 5: West Asians; Group 6: Arabs; Group 7: Europeans).

Some non-image-based studies analyzed the different patellar dimensions intra-operatively, using a caliper. Chahine Assi designed a new surgical technique to reproduce a native Patellofemoral Joint (PFJ) by identifying the preoperative position of the midpoint of the vertical articular ridge. Despite good follow-up results, this technique's reliability is indefinite due to the high interindividual variability of the patellar structure and nonspecific pattern for the cartilage degeneration and deformity during joint disease ${ }^{24}$. There are a few anthropometric investigations on gender, age, and ethnicity differences of the patella. One study considered the diseased patella, while another used CT scans or cadaveric specimens. Both ignored the precise measurement of the patellar cartilage in the healthy population ${ }^{25,26}$. These studies are neither reliable nor powerful to meet the normal patellar morphology, native patellar thickness, and to reproduce the normal knee joint biomechanics since they ignored the measurement of the patella's chondral structure.

Our study is on 927 knee MRIs with a normal patellar osteocartilaginous structure. We found a significant gender and age difference in all patellar diameters (thickness, width, length), with larger dimensions in males than females and younger than older individuals. Additionally, the average patellar 
thickness, width, and length were significantly different among the seven ethnic groups.

These findings may bring a new concept for the details of the patellar resurfacing technique and prosthesis design for each gender, age, and ethnicity. For instance, the prosthetic design and the resurfacing technique for a European man on his 30th and a 60-year-old woman from Far East Asia need to be significantly different; otherwise, patients will face serious complications.

Finding significant correlations between thickness, width, and length of the patella, provided us with sufficient information to precisely calculate the almost exact normal patellar thickness even in a patella with absent or eroded cartilage, using the other usually unaffected dimensions of that patella (width, length). (Equation 1) using this equation,

This is the first comprehensive study on age, gender, and ethnic specification of normal patellar morphology based on an extensive database of knee MRIs with normal patellar osteocartilaginous structure.

Previous studies predicted the normal patellar thickness relying upon only one parameter (patellar width). Considering one fixed normal factor has never been mathematically strong enough to predict the normal patellar thickness. While including two unaffected patellar dimensions (width and length) and three different demographic information (age, gender, and ethnicity), this study is supported by robust data for mathematical prediction of the patellar thickness.

This will raise the surgeon's confidence for more accurate determination of the patellar cutting size and guide more precise and specified designs of the new generations of the patellar implants. Besides, applying this information in forensic medicine could be essential in identifying the body's gender, age, and ethnicity.

We could not find an explanation for the significantly lower ridge offset ratio in middle age people (34-43 yr), even after randomly rechecking the measurements; hence, we are going to design a more extensive study to find out if this finding was a sampling error or an actual phenomenon happening in middle age people.

Three limitations should be noted about our study. First, we did not have access to the right and left MRI of each individual. Therefore, we could not compare the morphological aspects of the left and right patellae. Second, although we equalized all ethnic groups population with the random selection technique in SPSS software, the number of MRIs of Western Asians is significantly lower than in other groups. Third, we could not get knee MRIs from all ethnicities. Future studies are demanded to include normal patellar MRIs from both sides of each person and more equalization of participants in each ethnic group. Additionally, we need to include more ethnicities for future studies to have comprehensive information about this structure.

\section{Conclusion}

The ethnic differences in patellar dimensions found in this study can help optimize surgical technique and implant designs for patellar resurfacing.

The mathematical equation will help the surgeons to find the normal, pre-diseased thickness of the patella to prevent over-or under-stuffing during the patellar resurfacing; thus, improving the TKA outcome. Although this equation proved accurate in our study, it needs further validation to be used in clinical practice.

\section{References}

1. Grassi, A. et al. Patellar resurfacing versus patellar retention in primary total knee arthroplasty: a systematic review of overlapping meta-analyses. Knee Surgery, Sport. Traumatol. Arthrosc. 26, 3206-3218 (2018).

2. Calvisi, V., Camillieri, G. \& Lupparelli, S. Resurfacing versus nonresurfacing the patella in total knee arthroplasty: a critical appraisal of the available evidence. Arch. Orthop. Trauma Surg. 129, 1261-1270 (2009).

3. Bass, A. R. et al. Higher Total Knee Arthroplasty Revision Rates Among United States Blacks Than Whites. J. Bone Jt. Surg. 98, 2103-2108 (2016).

4. Fehring, T. K., Odum, S., Griffin, W. L., Mason, J. B. \& Nadaud, M. Early Failures in Total Knee Arthroplasty. Clin. Orthop. Relat. Res. 392, 315-318 (2001).

5. Lum, Z. C., Shieh, A. K. \& Dorr, L. D. Why total knees fail-A modern perspective review.

World J. Orthop. 9, 60-64 (2018).

6. Chawla, L. et al. Functional outcome of patellar resurfacing vs non resurfacing in 
Total Knee Arthoplasty in elderly: A prospective five year follow-up study. J. Arthrosc. Jt. Surg. 6, 65-69 (2019).

7. Putman, S., Boureau, F., Girard, J., Migaud, H. \& Pasquier, G. Patellar complications after total knee arthroplasty. Orthop. Traumatol. Surg. Res. 105, S43-S51 (2019).

8. Donell, S. Patellar tracking in primary total knee arthroplasty. EFORT Open Rev. 3, 106113 (2018).

9. Motsis, E. K., Paschos, N., Pakos, E. E. \& Georgoulis, A. D. Review Article: Patellar Instability after Total Knee Arthroplasty. J. Orthop. Surg. 17, 351-357 (2009).

10. Anglin, C. et al. Determinants of patellar tracking in total knee arthroplasty. Clin. Biomech. 23, 900-910 (2008).

11. Youm, Y.-S., Cho, W.-S., Woo, J.-H. \& Kim, B.$K$. The effect of patellar thickness changes on patellar tilt in total knee arthroplasty. Knee Surgery, Sport. Traumatol. Arthrosc. 18, 923927 (2010).

12. Abolghasemian, M. et al. Effect of Patellar Thickness on Knee Flexion in Total Knee Arthroplasty: A Biomechanical and Experimental Study. J. Arthroplasty 29, 80-84 (2014).

13. Choi, Y., Koo, J., Moon, S. W., Yang, Y. \& Son, J. Long-term Follow-up of Patellar Nonresurfacing in Total Knee Arthroplasty. Clin. Orthop. Surg. 12, 49 (2020).

14. Coory, J. A. et al. The Outcome of Total Knee Arthroplasty With and Without Patellar Resurfacing up to 17 Years: A Report From the Australian Orthopaedic Association National Joint Replacement Registry. J. Arthroplasty 35, 132-138 (2020).

15. Lygre, S. H. L., Espehaug, B., Havelin, L. I., Vollset, S. E. \& Furnes, O. Does patella resurfacing really matter? Pain and function in 972 patients after primary total knee arthroplasty. Acta Orthop. 81, 99-107 (2010).

16. Maradit-Kremers, H. et al. Is Selectively Not Resurfacing the Patella an Acceptable Practice in Primary Total Knee Arthroplasty? J. Arthroplasty 32, 1143-1147 (2017).
17. Harbaugh, C. M., Wilson, N. A. \& Sheehan, F. T. Correlating femoral shape with patellar kinematics in patients with patellofemoral pain. J. Orthop. Res. 28, n/a-n/a (2010).

18. Matz, J., Lanting, B. A. \& Howard, J. L. Understanding the patellofemoral joint in total knee arthroplasty. Can. J. Surg. 62, 5765 (2019).

19. Maiti, R., Fisher, J., Rowley, L. \& Jennings, L. $M$. The influence of kinematic conditions and design on the wear of patella-femoral replacements. Proc. Inst. Mech. Eng. Part HJ. Eng. Med. 228, 175-181 (2014).

20. Iranpour, F., Merican, A. M., Amis, A. A. \& Cobb, J. P. The Width:thickness Ratio of the Patella. Clin. Orthop. Relat. Res. 466, 11981203 (2008).

21. Huang, A.-B. et al. Comprehensive assessment of patellar morphology using computed tomography-based threedimensional computer models. Knee 22, 475480 (2015).

22. Jain, R., Kalia, R. B. \& Das, L. Anthropometric measurements of patella and its clinical implications. Eur. J. Orthop. Surg. Traumatol. 29, 1765-1769 (2019).

23. Sullivan, N. P. T. et al. Bristol index of patellar width to thickness (BIPWiT): A reproducible measure of patellar thickness from adult MRI. Knee 21, 1058-1062 (2014).

24. Assi, C., Kheir, N., Samaha, C., Chamoun, M. \& Yammine, K. Novel anatomical-based surgical technique for positioning of the patellar component in total knee arthroplasty. SICOT-J 3, 67 (2017).

25. Peckmann, T. R., Meek, S., Dilkie, N. \& Rozendaal, A. Determination of sex from the patella in a contemporary Spanish population. J. Forensic Leg. Med. 44, 84-91 (2016).

26. Kim, T. K., Chung, B. J., Kang, Y. G., Chang, C. B. \& Seong, S. C. Clinical Implications of Anthropometric Patellar Dimensions for TKA in Asians. Clin. Orthop. Relat. Res. 467, 10071014 (2009). 